\title{
Isotopic Variations in Terrestrial Xenon
}

\author{
W. A. Butuer, ${ }^{1}$ P. M. Jefrtery, ${ }^{2}$ J. H. Reynolds \\ Department of Physics, University of Califomia, Berkeley \\ G. J. WASSHRBURG \\ Division of Geological Sciences, California Institute of Technology, Pasadena
}

\begin{abstract}
Isotopic composition and amounts of zenon extracted from eclogite, from old granite, and from $\mathrm{CO}_{5}$-well gases have been measured. The $\mathrm{Xe}_{\mathrm{e}}$ content of Bavarian eclogite is close to that of the earth (assumed to be outgassed), and this Xe exhibits no isotope anomalies. Xenon from several old granite samples from the central Transvasl contains substantial amounts of fissionogenic $\mathrm{Xe}$ from spontaneous fission of $\mathrm{U}^{\mathrm{w}}$. Isotopic composition of this $\mathrm{Xe}$ is in agreement with values reported by Wetherill. The amount of fission $\mathrm{Xe}$ in amples from three related granites was very uniform, suggesting that U-Xe dating would be a valuable adjunct to K-Ar dating for old samples. Rough calculations of the U-Xe ages of these granites are in agreement with $\mathrm{Rb}-\mathrm{Sr}$ ages obtained by Allsopp. Xenon from the $\mathrm{CO}$-well gases contrined a component from spontaneous fission. The $\mathrm{H} \mathrm{e}^{4} / \mathrm{Xe}^{\mathbf{m a}}$, ratio for this gas is very close to that expected for gas evolved from rocks with a $\mathrm{Th} / \mathrm{U}$ ratio of 3 . In addition, there was a small component of excess $\mathrm{Xe}^{13}$, i.e., $\mathrm{Xe}^{100 *} / \mathrm{Xe}^{200},=0.92 \pm 0.42$. Arguments are given to show that this residual $\mathrm{Xe}^{20}$ is not due to fast or slow neutron absorption in $\mathrm{Te}^{2 w}$. The excess $\mathrm{Xe}^{10}$, if real appears to be due to decay, soon after formation of the earth, of now extinct 17-m.y. $\Gamma^{*}$. The effect has far-reaching implications: (1) it implies that the outgassing of the interior of the earth is not complete and that even the decay products of some short-lived activities have not been homogenized; (2) calculations based on an extremely simple model (but one for which results are fairly representative) give a rough indication of the time interval by which the earth postdates the meteorites. It is clear that further experiments with well gases should be made to see whether the effect is reproducible.
\end{abstract}

\section{INTRODUCTION}

In view of many interesting developments in the study of isotopic anomalies in $\mathrm{Xe}$ from meteorites (for recent accounts see, e.g., Clarke and Thode [1961], Krummenacher et al. [1962], Zâhringer [1962]), it has seemed important to exmine more closely the isotopic composition of $X_{e}$ from various terrestrial sources. Of unusual interest is the question whether differentiation of the earth took place before complete decay of 17-m.y. $I^{\infty}$, now known from meteorite studto to have been extant during the early history of the solar system. Another interesting question is whether any of the processes which led to the so-called general anomalies in isotopic composition of meteoritic $\mathrm{Xe}$ have left terrestrial traces.

I Permanent address: Department of Physics, Carleton College, Northfield, Minnesota.

${ }^{2}$ Permanent address: Department of Physics, University of Western Australia, Nedlands, Western Australia.
Some terrestrial variations in Xe are already known. Xenon from old uranium-bearing minerals is enriched relative to the atmosphere in fission Xe [Khlopin et al., 1947; Macnamara and Thode, 1950; Wetherill, 1953; Fleming and Thode, 1953]. Efforts to use $\mathrm{Xe}$ produced by fission for dating were reported by several workers [Gerling and Shokoliukov, 1959; Gerting et al., 1959]. If the U concentration in such minerals is not excessive, the fission $\mathrm{Xe}$ is predominantly from spontaneous fission of $\mathrm{J}^{\mathrm{m}}$, and it has been useful in determining spontaneous fission yields for this nuclide. Anomalous $\bar{X}_{e}$ has also been detected in old tellurium minerals; a slight excess of $\mathrm{Xe}^{\text {mos }}$ is attributed to double $\beta$ decay of $\mathrm{Te}^{100}$ [Inghram and Reynolds, 1950; Hayden and Inghram, 1951]. If the tellurium mineral was in association with $U$, there was also a marked excess of $\mathrm{Xe}^{\text {mo }}$ and $\mathrm{Xe}^{\mathrm{m}}$ from the $(n, \gamma)$ reaction in Te. Aside from these studies there has been little investigation of isotope variations in terrestrial Xe.

In the present work we have examined senon 
from three terrestrial sources. (1) Xenon from a Bavarian eclogite was examined as a sample which could possibly contain deep-seated terrestrial gas. (2) Xenon from three total-rock samples of the Old Granite of the central Transvaal was studied. These samples have been dated by the Rb-Sr method by Allsopp [1961]. The total-rock method gave consistent ages for the 3200-m.y.-old samples. Ages deduced from separated minerals from the samples varied, giving ages both higher and lower than the totalrock age and possibly reflecting a diffusion of $\mathrm{Rb}$ and Sr which occurred about 2000 m.y. ago, according to Allsopp. These samples were included in order to check whether any isotopic differences could be detected in ancient terrestrial Xe. Cameron [1962] has proposed a theory for the general anomalies in meteoritic $\mathrm{Xe}$ which includes the addition of anomalous $\mathrm{X}_{\mathbf{e}}$ to the atmosphere of the earth by the solar wind. If this addition has been gradual, ancient terrestrial Xe might differ in isotopic composition from that in the present-day atmosphere. (3) Xenon from two $\mathrm{CO}_{2}$-gas-wells in Harding County, New Mexico, was examined. One of these gas samples (Mitchell no. 4) was studied for He and Ar by Zartman et al. [1961]; who found a very high $A r^{\circ} / A r^{*}$ ratio $(22,500)$ and the lowest ratio of (He/Ar) rediozonle of any of the rock gases in that study. These data and the very high purity (99.9 per cent) of the $\mathrm{CO}$, suggested to these authors that the gas was derived from the decomposition of carbonate rocks by intrusive basalt under conditions in which gases and liquids were expelled into the nearby sediments before the $\mathrm{CO}_{2}$ accumulated. Under such conditions the $\mathrm{Xe}$ in the sample might be $\mathrm{ex}$ pected to reflect the isotopic composition of deep-seated terrestrial gas.

\section{Exxphrtmentat Methods}

All gas samples were analyzed statically in a glass mass spectrometer of high sensitivity [Reynolds, 1956] which utilizes a $60^{\circ}$ wedgeshaped magnet of 4.5-inch radius. Ions were detected with an electron multiplier. An apparatus for extracting and purifying the samples was connected directly to the mass spectrometer. It was used to prepare the eclogite sample (see details below) and to repurify other gas samples which had been prepared on a separate vacuum line. Air samples of approximately 0.04 coSTP were purified in this sample system, and the 6 tracted $X e$ was analyzed for calibration. The sensitivity of the spectrometer for $X_{e}$ s s termined by air runs at the time of the was $2 \times 10^{-20} \mathrm{ceSTP} / \mathrm{mv}$. For short-term work this sensitivity factor remains constant to witti about 20 per cent. For long-term work, we prefer to say that Xe quantities evaluated by the peak-height method are accurate to within factor of 3. The air Xe samples were also nod in determining the isotopic discrimination of the instrument, which results principally from in ence upon gain of the electron multiplier by the stray field from the main spectrometer maget The discrimination curve for the $X_{e}$ mass region is essentially a straight line when plotted versan mass number. An additional uncertainty in $X_{6}$ isotope ratios of 2.5 per mil per mass unit difference must be assigned because of mell fluctuations with time in the slope of this div crimination curve.

Eclogite scmple preparation. (Sample: berbach, Fichtelgebirge, Bavaria, Germany. Crushed in diamond mortar to minus 28 mech A weight of 3.78 grams of 28-150 mesh fraction taken for analysis.) Since preliminary runs had shown the amount of $\mathrm{Xe}_{\mathrm{e}}$ in the eclogite to be small, this sample was prepared directly in the sample system of the mass spectrometer, utilis ing a gas-extraction 'bottle' developed for mo orite studies. The sample, wrapped in aluminam foil, was dropped into a thoroughly outged molybdenum crucible by magnetic release. An outgassed lid was then released so as to cap th crucible. The sample was melted by RF inder tion heating in two steps: an hour of 'degasing' at $800^{\circ} \mathrm{C}$, as measured by a thermocouple bedded in the base of the crucible, and a 3 minute 'melting run' at $1600^{\circ} \mathrm{C}$. Gas from both heatings was examined, but the data presed are from the 'melting 'run' during which met of the gas was released. The gas was purified by exposure to hot titanium foil which was cocled in contact with the gas. The $\mathrm{Xe}$ fraction wa isolated quantitatively by adsorbing it on vated charcoal at $-70^{\circ} \mathrm{C}$ while the other ras gases were pumped away.

Granite sample preparation. (Bamples: Crushed whole-rock samples of Old Granite, tral Transvaal, South Africa, as follows: Wr koppen, 3.10 grams; Corlett Drive, 4.10 grams; Halfway House, 3.07 grams.) These sample 
were melted in an outgassed auxiliary system which included a gas extraction bottle similar to that used in the eclogite run described above. The gas was purified by exposure in turn to hot $\mathrm{CuO}$, a dry-ice trap, and hot (then cooled) Ti. The Xe fraction was isolated on charcoal at $-78^{\circ} \mathrm{C}$ in a Pyrex break-seal tube. Samples were repurified with $T i$ in the mass spectrometer sample system just before analysis.

CO,-well sample preparation. (Samples: Mitchell no. 4, about 50 caSTP of gas from this well [Carbonic Chemicals Corp.] in the Beuyeros field, Harding County, New Mexico. Method of collection and chemical analysis (99.9 per cent $\mathrm{CO}_{3}$ ) are described by Zartman et al. [1961] under the designation of sample 16 . Mitchell no. 7, about 160 ccSTP of gas from a well in the same field.) Xenon was extracted from these samples in a separate ultra-high vacuum line from which all chemicals were thoroughly outgassed before the sample was introduced. The $\mathrm{CO}$, was reacted with hot $\mathrm{KOH}$ in a nickel reaction tube. The gas was also oxidized by passing it repeatedly over hot $\mathrm{CuO}$, using chilled charcoal fingers to circulate the sample. The gas that remained was transferred to a section of the line where it was treated with hot (then cooled) Ti foil, destroying all but the rare gases. Xenon was finally isolated by adsorption on charcoal at $-78^{\circ} \mathrm{C}$ in a Pyrex break-seal tube. The $\mathrm{Xe}$ samples were repurified with $\mathrm{Ti}$ in the sample system of the mass spectrometer just before analysis.

\section{Results and Discussion}

Atmospheric xenon. All xenon isotope ratios in this paper have been referred to the atmospheric isotope abundances tabulated by Strominger et al. [1958], based on Nier [1950].

Eclogite sample. Xenon from the melting run' on this sample was $4 \times 10^{-11} \mathrm{ccSTP} / \mathrm{g}$. If the earth is completely outgassed, its $\mathrm{Xe}$ content is $6 \times 10^{-2 z} \mathrm{ccSTP} / \mathrm{g}$. Assuming that Bavarian eclogite has a gas content characteristic of the mantle of the earth, we could infer from these data that the $\mathrm{Xe}$ content of the earth, on the basis only of atmospheric Xe content, is correct to within a factor of 2 .

The isotopic composition of this gas, given in Table 1 , is normal within experimental error except at mass 124 . Little weight can be given to the mass 124 datum in this single run because of the very small total sample. The total amount of $\mathrm{Xe}^{12}$ analyzed was only about $2 \times 10^{-20}$ ccSTP, or 6 million atoms. As the instrument is presently operated the apparent excess-25 per cent of this-is very close to the detectability for $\mathrm{Xe}$.

Although atmospheric $\mathrm{Xe}$ occluded by the sample should have been largely removed by the preliminary heating, it is certain that a fraction of this gas was atmospheric Xe from outgassing of the apparatus. Thus the $\mathrm{Xe}$ content quoted above is an upper limit. It is still possible that eclogite contains very minute traces of $\mathrm{Xe}$ of abnormal composition. There are some eclogites for which formation at depth is entirely accepted by gelogists. Bavarian eclogite is not, unfortunately, of this class. It would be desirable to extend this work to some of the eclogites with less disputed modes of origin.

Granite somples. Xenon from the Old Granites, central Transvaal, was analyzed at a time when hydrocarbon background interferred with analyses at masses 124 and 126. A large $\mathrm{Xe}^{1 \mathrm{es}}$ 'memory' from previous runs with very anomalous samples interfered to some extent with the analysis at mass 128 . In other respects the analyses were satisfactory. Values of $\delta_{x}{ }^{(180)}$, i.e., fractional variations in the $M$ to 130 ratio in per mil referred to atmospheric Xe are listed in Table 2. The $\mathrm{Xe}^{128}$ concentrations are also listed. The isotope 130 is used as a standard for $\delta$ values because it is a 'shielded' isotope with respect to production by fission. All samples exhibit excess $\mathrm{X}_{\theta}$ at masses $131,132,134$, and 136, which are the isotopes produced in fission. Ratios of the $\delta$ values are listed in Table 3 . If the samples consist of mixtures, in varying proportions, of anomalous $\mathrm{Xe}$ of some constant composition and of atmospheric $\mathrm{Xe}$, the ratios of corresponding $\delta$ values will be the same for all samples. This is

TABLE 1. Isotopic Compasition of Xenon from Bavarian Eclogite $\delta_{M}(128)=1000\left[\left(\mathrm{Xe}^{N} / \mathrm{Xe}^{128}\right) /\left(\mathrm{Xe}^{M} / \mathrm{Xe}^{132}\right)_{\text {atmos }}-1\right]$ per mil

\begin{tabular}{lcccccccc}
\hline$M$ & 124 & 126 & 128 & 129 & 130 & 131 & 134 & 136 \\
$\delta_{x}(13)$ & $246 \pm 60$ & $-45 \pm 60$ & $12 \pm 19$ & $-15 \pm 14$ & $7 \pm 19$ & $-9 \pm 10$ & $-10 \pm 12$ & $21 \pm 19$ \\
\hline
\end{tabular}


TABLE 2. Isotopic Composition and Amount of Xenon from Old Granites, Central Trangras $\delta_{M}^{(130)}=1000\left[\left(\mathrm{Xe}^{M} / \mathrm{Xe}^{130}\right) /\left(\mathrm{Xe}^{M} / \mathrm{Xe}^{180}\right)_{\text {atmos }}-1\right]$ per mil

\begin{tabular}{|c|c|c|c|c|c|c|c|c|}
\hline \multirow[b]{2}{*}{ Sample } & \multirow{2}{*}{$\begin{array}{c}\text { Weight, } \\
\text { grams }\end{array}$} & \multicolumn{6}{|c|}{ Mass, $M$} & \multirow{2}{*}{ 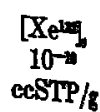 } \\
\hline & & 128 & 129 & 131 & 132 & 134 & 136 & \\
\hline $\begin{array}{l}\text { Witkoppen } \\
\text { Corlett }\end{array}$ & 3.10 & $<57$ & $4.3 \pm 10$ & $13.0 \pm 10$ & $34.0 \pm 9$ & $103.3 \pm 10$ & $142.8 \pm 10$ & 1.48 \\
\hline $\begin{array}{c}\text { Drive } \\
\text { Halfway }\end{array}$ & 4.10 & $<30$ & $-5.1 \pm 8$ & $5.9 \pm 8$ & $14.0 \pm 7$ & $43.3 \pm 8$ & $62.3 \pm 8$ & 3.64 \\
\hline House & 3.07 & $<85$ & $1.3 \pm 7$ & $14.3 \pm 7$ & $46.8 \pm 5$ & $172.9 \pm 7$ & $245.5 \pm 9$ & 0.91 \\
\hline
\end{tabular}

seen to be true, within experimental error. Since the 8 values for Halfway House are substantially more precise than the others, they have been used in our calculations.

In Table 4 the $\delta$ values have been converted to excess- $X_{\theta}$ ratios by assuming that the gas consists of an atmospheric component (contributing all the $\mathrm{Xe}^{\mathrm{x} 0}$ ) plus an excess component. This permits a comparison with $\mathrm{Xe}$ produced in spontaneous fission of $U^{-2}$ [Wetherill, 1953], also tabulated. Within experimental error these isotope ratios in Table 4 are seen to be identical, so that all the excess $X e$ in these samples can be attributed to this source.

The amounts of excess $\mathrm{Xe}^{100}$, expressed in millivolts of mass-spectrometer output per gram of sample, appear in Table 5. These amounts are remarkably constant for all three samples. The three mass-spectrometer analyses were made successively within a 48-hour period, so that the sensitivity of the instrument could be expected to remain quite constant throughout the series of runs. We conclude that the fission Xe component in these three granites is constant to within our present ability to measure this quantity. Applying our sensitivity factor of $2 \times 10^{-12} \mathrm{ccSTP} / \mathrm{mv}$

TABLE 3. Ratios of $\delta$ Values for Old Granites, Central Tranevaal

\begin{tabular}{|c|c|c|c|}
\hline Sample* & $\begin{array}{c}\delta_{131}(130) / \\
\delta_{128}(130) /\end{array}$ & $\begin{array}{c}\left.\delta_{132}(130)\right) / \\
\delta_{138}(130)\end{array}$ & $\begin{array}{l}\delta_{154}(130) / \\
\delta_{128}^{(120)}\end{array}$ \\
\hline $\begin{array}{l}\text { Witkoppen } \\
\text { Corlett }\end{array}$ & $.0910 \pm .07$ & $.238 \pm .07$ & $.723 \pm .086$ \\
\hline $\begin{array}{r}\text { Drive } \\
\text { Halfway }\end{array}$ & $.095 \pm .13$ & $.225 \pm .11$ & $.695 \pm .156$ \\
\hline House & $.058 \pm .028$ & $.191 \pm .02$ & $.705 \pm .038$ \\
\hline
\end{tabular}

* There are no significant differences among the xenon samples in this respect. we obtain an average fissionogenic $\mathrm{Xe}^{\mathrm{mm}}$ content $\mathrm{Xe}^{1+3}$, of $7.0 \times 10^{-19}$ ecSTP $\mathrm{Xe}^{\mathrm{im}}$, per gram

These results indicate that with refined tect niques U-Xe dating of old granites is feasible The age is computed from

$$
t=\tau \ln \left[\left(\mathrm{Xe}^{136} / \mathrm{U}^{238}\right) \cdot 1 / \alpha_{p} \cdot 1 / y_{136}+1\right]
$$

where $\tau$ is the mean life of $U^{m}\left(6.49 \times 10^{\circ}\right.$ years), $\alpha_{F}$ is the fraction of decays by sponts neous fission $\left(0.57 \times 10^{-0}\right)$, and $y_{180}$ is the fission yield of $\mathrm{Xe}^{13}$ in this process. Assuming $y_{m=}=$ 0.06 and a $U$ content of $3.7 \mathrm{ppm}$ (bosed on the recommended value for standard granite G-1; see, e.g., the compilation of Fleischer and Stev ens [1962]) we find

$$
t=3.0_{-1.8}^{+3.7} \times 10^{\circ} \text { years }
$$

The error on this age is very large because of the probably over-generous error of a factor of 3 we have assigned to the spectrometer sensitivity, but the result is in very satisfactory agreement with the age of $3.2 \times 10^{\circ}$ years measured by the $\mathrm{Rb}-$ Sr method [Allsopp, 1961 ].

The possibility of a new rare-gas method for dating old rocks is not without importance. At present much dating of old rocks is done by the $\mathrm{K}$-Ar method, but because of frequent instanes of Ar leakage in old rocks such determinations require checking by another method of dating (e.g. Rb-Sr or U-Pb). The U-Xe method would probably serve as an adequate check, since $\mathrm{X}_{e}$ leakage can be expected to differ substantially from Ar leakage; concordance would then indcate a closed system. Extraction and purification procedures for radiogenic Ar retain a fissionogenic $\mathrm{Xe}$ as well, so that in one sense the U-Xe method can be said to be partially 'built-in' to the K-Ar method.

CO,-well samples. The isotopic composition 
TABLE 4. Comparison of Excess Xenon Components in Halfway House, Old Granite with Xenon from Spontaneous Fission of U28s

\begin{tabular}{|c|c|c|c|c|}
\hline Sample* & $\left(\mathrm{Xe}^{2129} / \mathrm{Xe}^{120}\right)_{\text {exoeses }}$ & $\left(\mathrm{Xe}^{131} / \mathrm{Xe}^{\mathrm{InO}}\right)_{\text {exeen }}$ & $\left(\mathrm{Xe}^{182} / \mathrm{Xe}^{136}\right)_{\text {excess }}$ & $\left(\mathrm{X} \mathrm{e}^{134} / \mathrm{Xe}^{136}\right)_{\text {exoese }}$ \\
\hline $\begin{array}{l}\text { Halfway House } \\
\text { U2tion gpont. fission }\end{array}$ & $.016 \pm .085$ & $.138 \pm .067$ & $.579 \pm .061$ & $.830 \pm .045$ \\
\hline $\begin{array}{l}\text { [Wetherill, 1953] } \\
\text { Difference }\end{array}$ & $\begin{array}{c}<.002 \\
.016 \pm .085\end{array}$ & $\begin{array}{l}.076 \pm .003 \\
.062 \pm .067\end{array}$ & $\begin{array}{r}.595 \pm .010 \\
-.016 \pm .062\end{array}$ & $\begin{array}{r}.832 \pm .012 \\
-.002 \pm .047\end{array}$ \\
\hline
\end{tabular}

* The xenon samples are indistinguishable in this respect.

of $\mathrm{Xe}$ from the $\mathrm{CO}$, wells is given in Table 6. In Mitchell no. 7 well there are seen to be signifcant isotopic anomalies at masses $126,130,131$, 134 , and 136, if mass 132 is used as the reference isotope. All these anomalies occur also in Mitchell no. 4 well, although they are smaller there and, as in the case of mass 131, not always significant. The test of whether the two samples of

TABLE 5. Excess Xe $\mathrm{e}^{130}$ Content of Old Granites, Central Transvaal

\begin{tabular}{lc}
\hline Sample & $\begin{array}{c}\text { Excess Xe } \text { Content }^{186} \text { conts } \\
\text { (spectrometer millivolts/gram)* }\end{array}$ \\
\hline Witkoppen & $3.37 \pm 0.40$ \\
Corlett Drive & $3.69 \pm 0.66$ \\
Halfway House & $3.53 \pm 0.30$ \\
Average & $3.51 \pm 0.24$
\end{tabular}

- Spectrometer sensitivity is approximately $2 \times$ $10^{-\mathrm{b}} \mathrm{ceSTP} /$ millivolt.

Xe differ only in their content of atmospheric $\mathrm{X}_{\mathrm{e}}$ is to determine whether the ratio of a $\delta$ value for one sample to the corresponding $\delta$ value for the other sample is the same for all isotopes. This ratio has been computed whenever significant and is consistent with $\delta$ (no. 4) $/ \delta$ (no. 7) $=0.5$, within experimental error, for all isotopes. The two analyses are thus consistent with the existence of a single kind of anomalous $\mathrm{X} e$ in these rock gases-differences in $\delta$ values arise because of differing degrees of dilution with atmospheric $\mathrm{Xe}$.

Again a 'fission pattern' is suggested by the data, so that the choice of $\mathrm{Xe}^{100}$ as the standard isotope is to be preferred. Unfortunately, the analysis of gas from Mitchell no. 4 is useless here because we were able to obtain only an upper limit to the amount of $\mathrm{Xe}^{130}$ in the sample (i.e., $\left.\delta_{130}{ }^{(122)}<-6.6\right)$. Bad resolution of the mass spectrometer in the run on Mitchell no. 4 caused interference at mass 130 with the adjacent masses. (This difficulty, which has occurred intermittently in runs with the glass mass spectrometer, has been traced to faulty conducting coating on a portion of the glass analyzer tube and has since been corrected.) Mass 128 is totally inadequate as a standard isotope in the present work because of the large memory effect referred to above. In the following discussion, then, we are restricted to the data for Mitchell no. 7 .

In Table 7 we present the isotopic composition of $\mathrm{Xe}$ from Mitchell no. 7, referred to $\mathrm{Xe}^{\mathrm{rs0}}$ as the reference isotope. When so presented there appear to be excess amounts of $\mathrm{Xe}$ at masses $129,131,132,134$, and 136 . In Table 8 these data

TABLF 6. Iootopic Composition of Xenon from CO, Well, Harding County, New Mexico

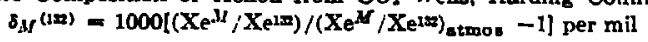

\begin{tabular}{|c|c|c|c|c|c|c|c|c|}
\hline & 124 & 126 & 128 & $\begin{array}{l}\text { Mass } \\
129\end{array}$ & $\begin{array}{ll}M & 130\end{array}$ & 131 & 134 & 136 \\
\hline Mitabell no. 4 & $-30.8 \pm 35$ & $-65.7 \pm 24$ & $4.2 \pm 50$ & $-3.1 \pm 9$ & $<-6.6$ & $-3.8 \pm 5$ & $15, \bar{n} \pm 5$ & $30.3 \pm 10$ \\
\hline Witehell no. 7 & $-5.6 \pm 28$ & $-35.5 \pm 21$ & $-14.3 \pm 23$ & $3.8 \pm 8$ & $-19.7 \pm 6$ & $-7.7 \pm 5$ & $32.7 \pm 8$ & $56.1 \pm 10$ \\
\hline $\begin{array}{l}\text { Ratio no. } 4 / \text { no. } 7 \\
\text { (where timifi- } \\
\text { ent) }\end{array}$ & & $1.8 \pm 1.3$ & & & & & $.47 \pm .18$ & $.54 \pm .20$ \\
\hline
\end{tabular}


TABLE 7. Isotopic Composition of Xenon from Mitchell No. $7 \mathrm{CO}_{2}$ Well, Referred to Xela as Reference Isotope

$$
\delta_{M}(130)=1000\left[\left(\mathrm{Xe}^{M} / \mathrm{Xe}^{130}\right) /\left(\mathrm{Xe}^{N S} / \mathrm{Xe}^{180}\right)_{\text {atmos }}-1\right] \text { per mil }
$$

\begin{tabular}{lcccccccc}
\hline$M$ & 124 & 126 & 128 & 129 & 131 & 132 & 134 & 136 \\
$\delta_{M}^{(120)}$ & $14.4 \pm 29$ & $-16.1 \pm 22$ & $5.5 \pm 24$ & $24.0 \pm 10$ & $12.2 \pm 8$ & $20.1 \pm 6$ & $53.5 \pm 10$ & $77.3 \pm 12$ \\
\hline
\end{tabular}

have been transformed to excess-Xe ratios for comparison with fission $\mathrm{Xe}$ from $\mathrm{U}^{2}$ spontaneous fission and from $U^{2 s}$ slow-neutron fission. The excess $\mathrm{Xe}$ from the sample closely resembles fission $\mathrm{Xe}$ from spontaneous fission of $\mathrm{U}^{\text {2at }}$. An appreciable contribution from slow-neutron fission of $\mathrm{U}^{2 m}$ is ruled out by the high $\mathrm{Xe}^{\mathrm{sen}} / \mathrm{Xe}^{100}$ ratio in the latter: it is highly unlikely that more than 5 per cent of the $\mathrm{Xe}^{\mathrm{Is}}$, is from that source. Accordingly, the component ascribed to spontaneous fission has been subtracted in Table 8. There remains a residue at mass 129 (129 residue $/ 136$ excess $=0.92 \pm 0.42$ ) and possibly at mass 131 (131 residue/136 excess $=0.30 \pm 0.26$ ).

We shall discuss the fission component first. The gas from the Mitchell wells is known [Zartman et $a l ., 1961]$ to contain $45 \mathrm{ppm}$ radiogenic He*. This is about 57 per cent from $\alpha$ decay of $\mathrm{U}^{\mathrm{w}}$ and its daughters if, as is most likely, the source is ascribed to relatively recent production in the rocks with $\mathrm{Th} / \mathrm{U}=3$. This amount of $\mathrm{He}^{4}$ should be accompanied by $(0.57)\left(45 \times 10^{-6}\right)$ $\left(0.57 \times 10^{-6}\right)(0.06) / 8=1.1 \times 10^{-13}$ atom fraction $\mathrm{Xe}^{\mathrm{ten}}$. The total $\mathrm{Xe}$ content of gas from Mitchell no. 7 is, subject to the rather large possible error in mass-spectrometer sensitivity discussed earlier, $13 \times 10^{-14}$ atom fraction. This corresponds to an excess $\mathrm{Xe}^{2 \omega}$ content of $0.9 \times$ $10^{-11}$ atom fraction. Within experimental error, this constitutes total agreement with the $X_{e} e^{m}$ predicted from spontaneous fission.

Turning finally to the residual $\mathrm{Xe}^{2 s}$ ponent, we recognize three possibilities. Firs, the residual is not real. This is possible but not likely because the effect ( $\mathrm{Xe}^{100}{ }_{\text {ros Idua }} / \mathrm{Xe}^{1000}{ }_{\text {azent }}=$ 0.92 ) is more than twice the assigned error, 0.42 Unfortunately, the run on Mitchell no. 4 is in conclusive on this point. If the weighted averaye of the ratios of $\delta$ 's from Table 6 is used to recosstruct the missing $\delta_{300}$ (ass) for Mitchell no. 4, we can compute the 129 residue for that run. The

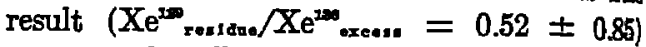
supports the effect, but not significantly.

The second possible explanation of the residual $\mathrm{Xe}^{100}$ is that it is real and is to be attributed to the $(n, \gamma)$ reaction on $\mathrm{Te}^{\mathrm{ins}}$. The neutrons af great underground depths originate from sportaneous fission of $\mathrm{U}^{20}$ and from $(\alpha, n)$ resctions induced by $\mathrm{U}$ and Th $\alpha$ particles [Wetheri], 1953 ; 1954]. Eugster [1954] has shown that such neutrons are more abundant than cosmic ray neutrons at great depths underground: the flux of neutrons detected in boron-loaded nuclesr emulsions was 26 times greater in a tunnel under 2100 meters of rock than at the surface of the earth at Berne, Switzerland. Inghram and Reynolds [1950] showed that neutrons from U ean indeed produce excess $\mathrm{Xe}^{20}$ in $\mathrm{Te}$; they found an excess of both $\mathrm{Xe}^{\mathrm{i}}$ and $\mathrm{Xe}^{\mathrm{in}}$ in an ancieat

TABLE 8. Comparison of Excess Component in Xenon from Mitchell No. $7 \mathrm{CO}_{2}$ Well with Xenon from Spontaneous Fission of $U^{228}$ (and from Neutron Fission of $U^{125}$ )

\begin{tabular}{|c|c|c|c|c|}
\hline Sample & $\left(\mathrm{Xe}^{189} / \mathrm{Xe}^{120}\right)_{\text {axeesi }}$ & $\left(\mathrm{Xe}^{12} / \mathrm{X} \mathrm{e}^{134}\right)_{\text {excos. }}$ & $\left(\mathrm{Xe}^{12} / \mathrm{Xe}^{130}\right)_{\text {exoens }}$ & $\left(\mathrm{Xe}^{12 \mathrm{x}} / \mathrm{Xe}^{15 x}\right)_{\text {menem }}$ \\
\hline $\begin{array}{l}\text { Xe from } \mathrm{CO}_{2} \\
\text { well }\end{array}$ & $.92 \pm .42$ & $.377 \pm .26$ & $.788 \pm .30$ & $.814 \pm .19$ \\
\hline $\mathrm{U}^{138}$ spont. fission & $<.002$ & $.076 \pm .003$ & $.595 \pm .010$ & $.832 \pm .012$ \\
\hline $\begin{array}{l}\text { (U) neutron } \\
\text { fission) }\end{array}$ & (.139) & $(.454)$ & (.678) & (1.248) \\
\hline Difference* & $.92 \pm .42$ & $.301 \pm .26$ & & \\
\hline
\end{tabular}

- There is an apparently significant residue of $\mathrm{Xe}^{129}$ after subtraction of U2s spontaneous fission renca. 
tellurium mineral which had been in association with U. Hayden and Inghram [1951] showed that a tellurium mineral of similar age, which bad not been in association with $U$, did not contain comparable amounts of excess $\mathrm{Xe}^{\mathrm{I0}}$ and $\mathrm{Xe}^{\mathrm{m}}$. In the Inghram-Reynolds experiment the ratio of $\mathrm{Xe}^{100}$ to $\mathrm{Xe}^{2 \mathrm{sil}}$ was 3.0. From thermal neutron cross sections we should expect this ratio to be 0.6 if thermal neutrons were responsible. This disparity suggests that fast neutrons are responsible for the production of the $\mathrm{Xe}$ isotopes. Let us suppose for the moment that fast neutrons are responsible. There are $2.4 \pm$ 0.2 fast neutrons emitted from spontaneous fission of $U^{2}$ [Littler, 1952]. We can estimate the number of additional neutrons from $(\alpha, n)$ reactions from Roberts' [1947] data, tabulated by Anderson [1948], on the neutron yields from thick targets bombarded by polonium $\alpha$ particles. Assuming that the $U$ resides in a rock of granitic composition, we expect 0.18 neutron per $10^{\prime} \alpha$ particles, using Roberts' values for neutron yields in $\mathrm{O}, \mathrm{Si}, \mathrm{Al}, \mathrm{Mg}$, and $\mathrm{Na}$. This gives 2.6 additional neutrons per spontaneous fission; Wetherill [1953] came to similar conclusions for Madagascar euxenite. Another 1.9 neutrons per spontaneous fission would arise from Th $\alpha$ particles in a rock where the $\mathrm{Th} / \mathrm{U}$ ratio is 3 . Combining, we expect $2.4+2.6+1.9=6.9$ neutrons per spontaneous fission. Since the spontaneous fission yield for $\mathrm{Xe}^{100}$ is about 6 per cent, there will be $6.9 / 0.06=115$ neutrons per $\mathrm{Xe}^{206}$. producing fission. Since we have seen that the 129 residue $/ 136$ excess $=0.92$, we conclude that, if the $\mathrm{Xe}^{10}$ residue is due to neutron absorption by $\mathrm{Te}^{1 \mathrm{w}}$, this reaction must occur once for every $115 / 0.92=125$ neutrons. We can estimate the least possible Te content which would lead to this result in the following way. Gibbons ei al. [1961] have plotted average neutron capture cross sections near $65 \mathrm{kev}$ as a function of $Z$. For $\mathrm{Si}$ the average cross section is about 2.1 millibarns. If we suppose that the rock is $\mathbf{5 0}$ per cent $\mathrm{SiO}_{2}$ and $x \mathrm{ppm} \mathrm{Te},(N \sigma)_{\mathrm{Te}}$ must be at least $1 / 125 \times(N \sigma)_{\text {a11 cor. }}$ For $\mathrm{Te}^{\mathrm{es}}, \sigma \approx 125$ millibarns. From this we conclude $x>450 \mathrm{ppm}$.

This far exceeds any conceivable concentration of $\mathrm{Te}$ in granite or diabase, where we might expect it to lie in the range 2 to $20 \mathrm{ppm}$. It appears that formation of the $\mathrm{Xe}^{100}$ residue from fast neutrons can be excluded.

Formation of this residue from absorption by
$\mathrm{Te}^{108}$ of thermal neutrons can also be excluded by the following argument. It is very unlikely that slow-neutron fission of $U^{205}$ has contributed more than 0.1 per cent of the excess $\mathrm{X}_{\theta^{200}}$. This upper limit can be set by supposing that all the neutrons from $U$ and $T h$ are moderated and then captured either by $\mathrm{Na}$ or by U⿻丷木 lecting the absorption of fast neutrons and the competing absorption of slow neutrons in elements other than $\mathrm{Na}$, we are greatly exaggerating the fraction absorbed in $\mathrm{U}^{20}$. Since there are 6.9 neutrons (see above) per spontaneous fission, there are $6.9 / 0.06=115$ neutrons per $\mathrm{Xe}^{\mathrm{wa}}$, produced by spontaneous fission. Assuming 2 per cent $\mathrm{Na}$ ( $\sigma=0.53$ barns) and $3 \mathrm{ppm} \mathrm{U}(\sigma=$ 582 barns for fission of $\left.\mathrm{U}^{2 \times 5}\right)$ we find $\left(\mathrm{Xe}^{\mathrm{se}}\right.$, nectrou $/\left(\mathrm{Xe}^{100}\right)_{\text {ppont. }} \leqq 0.8 \times 10^{-3}$. We get an experimental measure of the maximum contribution of slow-neutron fission of $U^{205}$ from the data on $\left(\mathrm{Xe}^{2 a} / \mathrm{Xe}^{100}\right)$ exees. in Table 8. The percentage of $\dot{\mathrm{X}} \mathrm{e}^{\mathrm{s}}$ due to slow-neutron fission deduced from the data in Table 8 is $0^{+\infty}-0$ per cent. The theoretical upper limit is much below the experimental one, and so we use the former in the calculation that follows. Returning to the question of $\mathrm{Xe}^{\mathrm{I00}}$ from slow neutrons on $\mathrm{Te}^{23}$, and taking 10 as a reasonable terrestrial value for the $\mathrm{Te} / \mathrm{U}$ atomic ratio (based on values by Goles and Anders [1962] for this ratio in various classes of meteorites), we would expect the ratio of production of $\mathrm{Xe}^{10}$ from $\mathrm{Te}^{130}$ $\left(\sigma=0.14\right.$ barn) to $\mathrm{Xe}^{100}$ from $U^{2 a s}$ fission ( $\sigma=$ 582 barns, $\mathrm{Xe}^{\mathrm{ma}}$ yield $=6$ per cent) to be 1.8 . But as we have seen, the ratio based on measurement of excess $\mathrm{Xe}^{10}$ and calculation concerning excess $\mathrm{Xe}^{20}$, is greater than $(0.92-0.42)$ / $10^{-4}=500$. We have subtracted the probable error of 0.42 from the value 0.92 in order to arrive at a conservative number. The discrepancy between 1.8 and $\geqq 500$ requires some mechanism other than slow-neutron absorption on $\mathrm{Te}^{\mathrm{i}}$ for the $\mathrm{Xe}^{\mathrm{im}}$ production.

The third possible explanation of the excess $\mathrm{Xe}^{\mathrm{t}}$ is that it was produced by the decay of 17-m.y. $\Gamma^{\mathbf{m}}$ very early in the history of the earth. This would mean that the outgassing of the earth's interior is incomplete and that the decay products of such short-lived elements as $\Gamma^{\mathbf{m}}$ have not been homogenized. This suggests that $\mathrm{Xe}^{20}$ and possibly other such daughter isotopes are presently being added to the atmosphere and the upper crust. It follows that thorough con- 
vective mixing and outgassing did not occur during the early stages in the differentiation of the earth.

It is instructive to attempt to calculate a 'formation interval' for the earth, assuming the excess $\mathrm{Xe}^{100}$ to be from $\mathrm{I}^{120}$ decay. The formation interval for a system is defined as the time interval between the end of nucleosynthesis and the point in time when the system began quantitatively to retain radiogenic $\mathrm{Xe}^{100}$. We suppose that the system has been closed with respect to $\mathrm{U}, \mathrm{I}$, and daughter $\mathrm{Xe}$ for $4.6 \times 10^{\circ}$ years. We shall suppose that the atomic ratio I/U is 10 on the basis of meteoritic values by Goles and Anders [1962]. Then

$$
\frac{\mathrm{Xe}^{129 *}}{\mathrm{I}^{127}}=\left(\frac{\mathrm{U}^{238}}{\mathrm{I}^{127}}\right) \times\left(\frac{\mathrm{Xe}^{136}{ }_{F}}{\mathrm{U}^{238}}\right) \times\left(\frac{\mathrm{Xe}^{129 *}}{\mathrm{Xe}^{136}{ }_{F}}\right)
$$

The first expression on the right-hand side is 0.1 by hypothesis, the second is $3.4 \times 10^{-8}$ from decay constants of $U$ and the assumed age of $4.6 \times 10^{\circ}$.years, and the third is 0.92 by measurement. Thus $\mathrm{Xe}^{100 *} / \mathrm{I}^{20}=3.1 \times 10^{-0}$.

If we take as the ratio of $\mathrm{I}^{\infty 0} / \mathrm{I}^{20}$ at the end of nucleosynthesis the value 0.00125 given by continuous galactic synthesis over an effective period of $20 \times 10^{\circ}$ years [Cameron, 1962], we obtain a formation interval of $320 \mathrm{~m} . \mathrm{y}$.

This formation interval cannot be taken very seriously in an absolute sense if we stop to consider the role which $\mathrm{Pu}^{\mathrm{m}}$ would play in this scheme. Present at the end of nucleosynthesis with an abundance of about $1 / 60$ of $\mathrm{U}^{20}$ it would generate about twenty times as much spontaneous fission $\mathrm{Xe}$ in our system as is generated by $\mathrm{U}^{\mathrm{mes}}$. Since it seems very likely from the isotopic composition of the fission component and from the $\mathrm{Xe}^{130} / \mathrm{He}^{4}$ ratio that it was produced by spontaneous fission of $U^{2 \infty}$, we probably cannot adopt both our simple closed model and the hypothesis of galactic synthesis. If the $\Gamma^{\text {were }}$ produced by some process which did not produce $\mathrm{Pu}^{24}$ along with it [Fowler et al., 1962] and if its production in meteorites was the same relative to $\mathrm{I}^{27}$ as in the terrestrial material, the difference in formation intervals calculated for meteorites and the earth would be significant. Latest results for the formation intervals of stone meteorites [Reynolds, 1963] give values in the range 35 to $52 \mathrm{~m} . \mathrm{y}$. This suggests that the earth postdates the meteorites by about $270 \mathrm{~m} . \mathrm{y}$. Even this conclusion cannot be given much weight at present because of the extreme nature of the assumptions made in setting up the closed-system model, but the general character of the computation is instructive.

Note added in proof. We have just seen thesis by W. B. Clarke (McMaster University, 1963), who has examined, among other things, gas from a helium well in which there was substantial fission Xe component. He finds val ues of $\left(\mathrm{Xe}^{150} / \mathrm{Xe}^{100}\right)_{\text {oxcess }}$ and $\left(\mathrm{Xe}^{100} / \mathrm{Xe}^{100}\right)_{-}$ ces. which, like those in Table 8 , are higher then for spontaneous fission of $\mathrm{U}^{200}$ as determined by Wetherill, but which in his work cannot be dis missed as a result of experimental error. He has noted similar and very striking examples of excess $\mathrm{Xe}^{\mathrm{ing}}$ and $\mathrm{Xe}^{\mathrm{ing}}$ in the first few per cent of gas released by heating from neutron-irradiated $\mathrm{U}$ compourds; there the excess can be explained if the radioactive precursors of the fission $X_{t}$ diffuse preferentially in the lattice of the $U$ compound. To invoke this mechanism to explain the composition of fission $\mathrm{Xe}$ in gas wells requires rather special circumstances for the outgassing of $\mathrm{Xe}$ from rocks. Clarke also notes a hint of excess $\mathrm{Xe}^{10}$ in his sample, which is in agreement with our work on an absolute basis for gas content, but not on a relative basis-i.e., when referred to the fission component which is mueb more abundant in the well he studied. We are grateful to Dr. Clarke for the opportunity to his data before the publication of his paper.

Acknowledgments. We wish to thank Professor F. J. Turner for the eclogite sample and Dr. H. L. Allsopp for the samples of Old Granite.

This work received support from the $J . \&$. Atomic Energy Commission as well as supplementary support from the Institute of Geophysics of the University of California and the Alfred P. Sloan Foundation.

\section{REFERENCES}

Allsopp, H. L., Rb-Sr age measurements on total rock and separated-mineral fractions from the Old Granite of the central Transvaal, J. Geophys. Res., 66, 1499, 1961.

Anderson, H. L., Neutrons from alpha-emitters, Prelim. Rept. S, unpublished, Nuclear Science Series, National Research Council 1948.

Cameron, A. G. W., The formation of the sun and planets, Icarus, 1, 13, 1962.

Clarke, W. B., and H. G. Thode, Xenon in the Bruderheim meteorite, J. Geophys. Res, 66, 3578, 1961.

Eugster, J., Neutron measurements at great underground depths, Rev. Sci. Instr., 25, 5, 1954. 
Fleischer, Michael, and R. E. Stevens, Summary of new data on rock samples G-1 and W-1, Geochim. Cosmochim. Acta, 26, 525, 1961.

Fleming, W. H., and H. G. Thode, Neutron and spontaneous fission in uranium ores, Phys. Rev. g*, 378, 1953.

Fowler, W. A.2 J. L. Greenstein, and F. Hoyle, Nucleosynthesis during the early history of the solar system, Geophys. J, 6, 148, 1962.

Gerling, E. K, and E. A. Shokoliukov, Isotopic composition and amounts of zenon in uranium minerals, Akad. Nauk SSSR Radiochemistry, 1(2), 212, 1959.

Gerling, E. K., E. A. Shokoliukov, and A. Makarochkin, Determination of the half-life of spontaneous fission of $U^{2 x}$ in uranium minerals, Akad. Nauk, SSSR Radiochemistry, 1(2), 223, 1959.

Gibbons, J. H., R. L. Macklin, P. D. Miller, and J. H. Neiler, Average radioactive capture cross sections for 7- to 170 -kev neutrons, Phys. Rev. 182, 182, 1961.

Goles, G. G., and E. Anders, Abundances of iodine, tellurium, and uranium in meteorites, Geochim. Cosmochim. Acta, 26, 723, 1962.

Hayden, Richard J., and Mark G. Inghram, Further results on the double beta decay of $\mathrm{Te}^{100}$, in Mass Spectroscopy in Physics Research, Proceedings of the NBS Semicentennial Symposium on Mass Spectroscopy in Physics Research, September 1951, issued as Natl. Bur. Std, U. S. Circ. 6\%2, 1953.

Inghram, M. G., and J. H. Reynolds, Double betadecay of $\mathrm{Te}^{130}$, Phys. Rev., 78, 822, 1950.

Khlopin, V. G., E. K. Gerling, and N. V. Baronovskoys, Natural occurrence of some stable products of spontaneous fission of uranium, Bull. Acad. Sci. USSR Classe Sci. Chim., 699, 1947; Chem. Abs., 48, 3664, 1948.

Krummenacher, D., C. M. Merrihue, R. O. Pepin, and J. H. Reynolds, Meteoritic krypton and barium versus the general isotopic anomalies in meteoritic xenon, Geochim. Cosmochim. Acta, 26, 231, 1962.

Littler, D. J, A determination of the rate of emission of spontaneous fission neutrons by natural uranium, Proc. Phys. Soc., London, A, 65, 203, 1952.

Macnamara, J., and H. G. Thode, The isotopes of xenon and krypton in pitchblende and the spontaneous fission of U , Phys. Rev., 80, 471, 1950.

Nier, A O, A redetermination of the relative abundances of the isotopes of neon, krypton, rubidium, xenon, and mercury, Phys. Rev., 79, 450, 1950.

Reynolds, J. H., High sensitivity mass spectrometer for noble gas analysis, Rev. Sci. Instr., 87, $928,1956$.

Reynolds, J. H., Xenology, J. Geophys. Res., 68 (10), 1963.

Roberts, J. H., Neutron yields of several light elements bombarded with polonium alpha particles, U. S. At. Energy Comm. Rept. MDDC-7\$1, 1947, unpublished.

Strominger, D., J. M. Hollander, and G. T. Seaborg, Table of isotopes, Rev. Mod. Phys., 30, $585,1958$.

Wetherill, G. W., Spontaneous fission yields from uranium and thorium, Phys. Rev., 92, 907, 1953.

Wetherill, G. W., Variations in the isotopic abundances of neon and argon extracted from radioactive minerals, Phys. Rev., 96, 679, 1954.

Zähringer, J., Isotopie-Effekt und Häufigkeiten der Edelgase in Steinmeteoriten und auf der Erde, Z. Naturforsch., 17a, 460, 1962.

Zartman, R. E., G. J. Wasserburg, and J. H. Reynolds, Helium, argon, and carbon in some natural gases, J. Geophys. Res., 66, 277, 1961.

(Manuscript received January 21, 1963; revised March 7, 1963.) 